\title{
Prehospital emergency medical services' ethical dilemma with do-not-resuscitate orders
}

\author{
Jonathan Sherbino, BSc;* Veena Guru, BSc; † P. Richard Verbeek, MD;đI Laurie J. Morrison, MDI
}

\begin{abstract}
Objectives: Our primary objectives were to estimate how frequently emergency medical technicians with defibrillation skills (EMT-Ds) are forced to deal with prehospital do-not-resuscitate (DNR) orders, to assess their comfort in doing so, and to describe the prehospital care provided to patients with DNR orders in a system without a prehospital DNR policy (i.e., where resuscitation is mandatory).

Methods: Using Dillman methodology, the authors developed a 13-item survey and mailed it to 382 of 764 EMT-Ds in the metropolitan Toronto area. Responses were evaluated using 5-point Likert scales, limited-option and open-ended questions. Narrative responses were categorized. Two authors independently categorized narrative responses from 20 surveys, and kappa values for agreement beyond chance were determined.

Results: Among 382 EMT-Ds surveyed, 236 (62\%) responded, of whom 221 (94\%) answered the questionnaire. Overall, 126 of $219(58 \%)$ indicated that they were called to resuscitate patients with DNR orders "sometimes, " "frequently," or "all the time." In such situations, 22 of 207 (11\%) stated they would honour the DNR order and 55 of 207 (27\%) would honour the order but appear to provide basic resuscitation, in order to adhere to mandatory resuscitation regulations. Willingness to honour a DNR order did not vary by years of emergency medical service. EMT-Ds cited concern for the family and the patient, fear of repercussions and conflict with personal ethics as key factors contributing to this ethical dilemma. If legally allowed to honour DNR orders, 212 of 221 (96\%) respondents would be comfortable with a written order and 137 of 220 (62\%) with a verbal order.

Conclusions: Prehospital DNR orders are common, and a significant number of EMT-Ds disregard current regulations by honouring them. EMT-Ds would be more comfortable with written than verbal DNR orders. An ethical prehospital DNR policy should be developed and applied.

\section{RÉSUMÉ}

Objectifs : Nos principaux objectifs étaient d'estimer la fréquence à laquelle des techniciens médicaux d'urgence ayant une formation en défibrillation (TMU-D) sont confrontés à des demandes de ne pas réanimer en situation pré-hospitalière, d'évaluer leur niveau de confort face à de telles situations et de décrire les soins pré-hospitaliers administrés aux patients ayant fait une demande de ne pas réanimer au sein d'un système doté d'aucune politique à ce sujet en situation pré-hospitalière (i.e. la réanimation est obligatoire).

Méthodes: À l'aide de la méthodologie de Dillman, un sondage en 13 points fut élaboré et envoyé par la poste à 382 des 746 TMU-D de la région métropolitaine de Toronto. Les réponses furent évaluées à l'aide d'échelles de Likert en 5 points, de questions à choix limités et de questions à développement. Les réponses à développement furent classées. Deux auteurs (P.R.V. et L.J.M.) classèrent indépendamment les réponses à développement provenant de 20 sondages et les valeurs kappa pour une concordance non aléatoire furent déterminées.
\end{abstract}

\footnotetext{
*Faculty of Medicine, University of Ottawa, Ottawa, Ont.; †Faculty of Medicine, University of Toronto, Toronto, Ont.; ๆAssistant Professor, Division of Emergency Medicine, University of Toronto, and Sunnybrook \& Women's College Health Sciences Centre, Toronto Received: Oct. 29, 1999; final submission received: June 7, 2000; accepted: June 22, 2000.
}

This article has been peer reviewed. 
Résultats : Parmi les 382 TMU-D ayant reçu le sondage, 236 (62 \%) répondirent, dont 221 (94\%) répondirent au questionnaire. Parmi ceux-ci, 126/219 (58 \%) indiquèrent qu'ils avaient été appelés pour réanimer des patients ayant fait une demande de ne pas réanimer "parfois», "souvent» ou "tout le temps.» Dans de telles situations, 22/207 (11\%) affirmèrent qu'ils respecteraient la demande de ne pas réanimer et 55/207 (27\%) respecteraient la demande mais feraient semblant d'administrer la réanimation de base afin d'obéir aux règles de réanimation obligatoire. La volonté de respecter une demande de ne pas réanimer ne variait pas selon le nombre d'années de service. Les TMU-D mentionnèrent un souci de la famille et du patient, la peur de répercussions et les conflits d'éthique personnelle comme facteurs clés contribuant à ce dilemme éthique. Si la loi leur permettait de respecter les demandes de ne pas réanimer, 212/221 (96\%) des répondants seraient à l'aise avec une demande écrite et 137/220 (62\%) avec une demande verbale.

Conclusions : Les demandes de ne pas réanimer en situation pré-hospitalière sont courantes et un nombre important de TMU-D les respectent, défiant les règles présentement en place. Les TMU-D préféreraient des demandes écrites plutôt que verbales. Une politique éthique sur les demandes de ne pas réanimer en situation pré-hospitalière devrait être élaborée et appliquée.

Key words: emergency medical services, resuscitation orders, medical ethics

\section{Introduction}

In an environment of hospital closures, increased utilization of home care and an aging population, more patients are opting for palliative care and death in non-hospital settings. At the time of death, the Emergency Medical Services (EMS) system is frequently activated, necessitating a paramedic response. Common reasons for EMS system activation at the time of expected death include, but are not limited to, panic on the part of family or caregivers, a need for body removal and the belief that basic emergency medical technicians with defibrillation skills (EMT-Ds) can issue a pronouncement of death.

Since 1995, 25 US states have developed specific policies enabling paramedics to honour do-not-resuscitate (DNR) orders in the prehospital setting. ${ }^{1}$ In 1996, the American College of Emergency Physicians issued a statement directing all EMS programs to develop a comprehensive prehospital DNR policy. ${ }^{2}$ Despite this directive, many EMS programs in the United States still lack a defined protocol permitting EMT-Ds to honour DNR orders. ${ }^{1}$

There are no published data on the Canadian EMS system's DNR policies. Where such policies do not exist, paramedics face an ethical dilemma. In Ontario, EMT-Ds are required to violate the patient's (DNR) wishes and obey current regulations by initiating resuscitation. ${ }^{3}$ In contrast to advanced care paramedics, EMT-Basic (EMT-Bs) and EMT-Ds in Ontario have the added problem of being unable to contact a base hospital physician to request pronouncement of death in the field.

Regulations that fail to recognize prehospital DNR orders lead to several problems. Patients' wishes are ignored, ${ }^{4}$ family members and friends face prolonged suffering prior to their loved one's inevitable death, ${ }^{5}$ fewer patients may opt for outpatient palliative care for fear their DNR order will be ignored, unwanted resuscitations tie up paramedic resources $^{6}$ and paramedics face added emotional stress. ${ }^{7}$

Our a priori hypotheses were: 1) that EMT-Ds frequently encounter situations where they are required to resuscitate palliative care patients with DNR orders; 2) that a significant proportion of EMT-Ds comply with patient DNR orders and therefore disobey current regulations; 3) that more experienced EMT-Ds are more likely to comply with patient DNR orders; and 4) that the majority of EMT-Ds are comfortable honouring a patient's DNR order.

\section{Methods}

\section{Design}

A descriptive, cross-sectional survey of the EMT-Ds in the Toronto area.

\section{Setting}

The metropolitan Toronto EMS system serves 2.5 million people and has an annual call volume of 450,000 . This system is under the control of a medical director, who provides offline quality assurance without online medical delegation. Offline medical control is remote from the point of care (e.g., chart review or delegation by protocol). Online medical control refers to medical delegation over the phone at the time of patient contact. EMT-Ds respond to $50 \%$ of all critical calls and are skilled in the management of chest pain, asthma, hypoglycemia and allergic reactions. They are permitted to administer nitroglycerin, ASA, salbutamol, glucagon and epinephrine according to standardized proto- 
cols. They are unable, or not encouraged, to communicate with an EMS base hospital physician from the point of care. EMT-Ds are not required to initiate the resuscitation of a person with absent vital signs in the setting of decapitation, rigor mortis or body decomposition. ${ }^{3}$

\section{Instrument development}

A focus group of practising EMT-Ds developed the survey. An expert panel, including the Chief Coroner, the Medical Director of the EMS Defibrillation Program, a palliative care physician, emergency physicians and a medical lawyer, reviewed the survey for face and content validity, comprehensibility, and to identify sources of ambiguity. The survey was then piloted on 10 EMT-Ds. It consisted of 7 questions using a 5-point Likert scale (never/rarely/ sometimes/frequently/all the time), 4 open-ended, narrative-response questions, and 3 questions with a limited option (single choice) response. Copies of the survey are available on request.

\section{Subject recruitment and ethical approval}

All analyses were descriptive; therefore, a sample size calculation was not performed. All 788 currently employed EMT-Ds were listed alphabetically and every second one was invited to participate. The mail survey was conducted between June and September of 1998, using the Dillman methodology for mail and telephone surveys, which is

\begin{tabular}{|c|c|c|c|c|}
\hline Week & Step & $\begin{array}{c}\text { Expected } \\
\text { response } \\
\text { rate, } \%\end{array}$ & $\begin{array}{l}\text { Expected } \\
\text { cumulative } \\
\text { response } \\
\text { rate, \% }\end{array}$ & $\begin{array}{l}\text { Actual } \\
\text { cumulative } \\
\text { response } \\
\text { rate, \% }\end{array}$ \\
\hline 1 & $\begin{array}{l}\text { Introduction letter with } \\
\text { option to withdraw }\end{array}$ & & & \\
\hline 3 & $\begin{array}{l}\text { Cover letter, survey, } \\
\text { and response card }\end{array}$ & 25 & 25 & 25 \\
\hline 5 & $\begin{array}{l}\text { Reminder letter to } \\
\text { nonresponders; option } \\
\text { to fax a survey request }\end{array}$ & 10 & 35 & 35 \\
\hline 9 & $\begin{array}{l}\text { Second cover letter, } \\
\text { survey and response } \\
\text { card to nonresponders }\end{array}$ & 15 & 50 & 50 \\
\hline 11 & $\begin{array}{l}\text { Second reminder to } \\
\text { nonresponders; option } \\
\text { to fax a survey request }\end{array}$ & 10 & 60 & 55 \\
\hline 15 & $\begin{array}{l}\text { Telephone call by the } \\
\text { principal investigator } \\
\text { to nonresponders }\end{array}$ & 10 & 70 & Deferred* \\
\hline $\begin{array}{l}* \text { During } \\
\text { addressec } \\
\text { EMT-Ds } \\
\text { response }\end{array}$ & $\begin{array}{l}\text { final step the EMT-D union } \\
\text { sugh a modification of the Dillm } \\
\text { e target sample and a third mai } \\
\text { of } 62 \% \text {. }\end{array}$ & $\begin{array}{l}\text { sed concern } \\
\text { methodology } \\
\text { of the surve }\end{array}$ & $\begin{array}{l}\text { ut privacy, w } \\
\text { union sent a le } \\
\text { s undertaken. T }\end{array}$ & $\begin{array}{l}\text { were ultimately } \\
\text { of endorsement tc } \\
\text { esulted in a fina }\end{array}$ \\
\hline
\end{tabular}

designed to achieve a response rate of at least $70 \%$ (Table 1). ${ }^{8}$ Twelve paramedics could not be contacted at their last known postal address; thus, a convenience sample of 382 was established. Participation was voluntary, confidential and anonymous, and consent was implicit in survey completion. The option of not participating was provided on the response card. Each response card was numbered to allow for the removal of identifying information from the database upon receipt of the mailed card. The Institutional Review Board approved this study.

\section{Data management}

To maximize accuracy and reduce inconsistencies, standardized data abstraction techniques were employed. ${ }^{9}$ These included abstractor training, regular meetings with the principal investigator (L.J.M.), performance monitoring and interrater testing. Double data entry was conducted for all of the surveys. Narrative responses were grouped into categories established by the principal investigator and the primary data abstractor (J.S.) using a pilot sample of 25 returned surveys. All narrative responses in a sample of 20 of the remaining surveys were independently re-categorized by the principal investigator to assess the inter-rater reliability of classification.

\section{Data analysis}

Frequencies and percentages were calculated for limitedoption and Likert-scaled responses, as well as the categories generated for the open-ended questions. The relationship between years of experience and compliance with DNR orders was assessed using analysis of variance (ANOVA). The kappa statistic, which measures agreement beyond chance, ${ }^{10}$ was calculated to determine inter-rater reliability between the principal investigator and data abstractor in the classification of open-ended questions.

\section{Results}

Of 382 EMT-Ds surveyed, 236 (62\%) responded and $221(93.2 \%)$ of these chose to participate. Average length of service for respondents was 14 years (range from 1 to 30 years). Overall, 126 (58\%) of 219 EMT-Ds indicated that they encountered the resuscitation of a palliative care patient with a DNR order "Sometimes," "Frequently" or "All the time." In this situation, 160 (76\%) of 210 indicated that they felt "Uncomfortable" or "Extremely uncomfortable" with current regulations requiring the resuscitation of all patients (Table 2). 
A total of 212 respondents identified problems generated by the current regulations (Table 3). "Concern for patient's family" ( $n=89)$, fear of "Disciplinary/legal repercussions" ( $n=$ $75)$ and "Conflict with personal ethics" $(n=74)$ were the most frequently cited problems. Item non-response was observed for some of the questions, particularly those addressing the way paramedics respond to DNR orders (14 missing) and how they feel about current regulations (11 missing).

The level of agreement for categorization of open-ended question responses ranged from fair to almost perfect. ${ }^{11}$ Agreement was fair in the "System concerns" and "Credibility of DNR order" categories (kappa $=0.22$ and 0.31 , respectively); very good in the "Conflict with personal ethics" and "Concern for patient's family" categories (kappa $=0.77$ and 0.78 ) and almost perfect in the "Concern for patient" and "Disciplinary/legal repercussions" categories (kappa $=0.82$ and 0.85 ).

Given a hypothetical situation where they could legally comply with a DNR order, 197 (89\%) of 221 respondents said they would be "Extremely comfortable" or "Comfortable" with a written DNR order, while only 97 (44\%) of 220 paramedics had this level of comfort with a verbal DNR order (Table 4).

Of 207 EMT-Ds who disclosed how they would respond to a DNR order in a palliative care patient, $130(63 \%)$ would disregard the DNR order and initiate resuscitation, $22(11 \%)$ would honour the DNR order and $55(27 \%)$ would honour the DNR order but appear to provide basic resuscitation. There was no association between years of EMT-D service and willingness to honour a DNR order $(p=0.47)$.

Of 213 respondents who suggested changes to the existing system, $126(59 \%)$ indicated that a policy change allowing EMT-Ds to honour DNR orders was necessary, 81 (38\%) felt that a standardized system should be developed, $43(20 \%)$ suggested public education about current EMS resuscitation guidelines, $23(11 \%)$ believed that radio access to a base hospital physician for a pronouncement of death in the field would be helpful and $15(7 \%)$ wanted legal backup for paramedics.

Agreement was substantial in the policy change and system standardization categories (kappa $=0.62$ and 0.77 , respectively), and was almost perfect in the public education, physician access and legal backup categories (kappa $=$ $0.85,1.0$ and 1.0).

\section{Discussion}

In this study, EMT-Ds reported that they often encounter palliative care patients with DNR orders. This presents an ethical dilemma, in which the EMT-D must either violate regulations and honour the patient's wishes, or adhere to regulations and initiate an unwanted resuscitation. Our data demonstrate a high degree of EMT-D discomfort with the current regulations, which require resuscitation of all patients.

\begin{tabular}{|c|c|}
\hline & No. $(\%)$ \\
\hline \multicolumn{2}{|l|}{$\begin{array}{l}\text { Frequency of encounter } \\
(n=219)\end{array}$} \\
\hline Never & $21(9.6)$ \\
\hline Rarely & $72(32.9)$ \\
\hline Sometimes & $83(37.9)$ \\
\hline Frequently & $42(19.2)$ \\
\hline All the time & $1(0.5)$ \\
\hline \multicolumn{2}{|l|}{$\begin{array}{l}\text { Comfort with regulations } \\
\text { requiring resuscitation } \\
(n=210)\end{array}$} \\
\hline Extremely comfortable & $16(7.6)$ \\
\hline Comfortable & $19(9.1)$ \\
\hline Somewhat comfortable & $15(7.1)$ \\
\hline Uncomfortable & 88 (41.9) \\
\hline $\begin{array}{l}\text { Extremely } \\
\text { uncomfortable }\end{array}$ & $72(34.3)$ \\
\hline
\end{tabular}

Table 3. Problems identified by paramedics under current regulations requiring resuscitation of all patients $(n=212)$

\begin{tabular}{|c|c|c|}
\hline Problem & No. $(\%)$ & Kappa \\
\hline $\begin{array}{l}\text { Concern for patient's family (i.e., emotional } \\
\text { trauma of unwanted resuscitation) }\end{array}$ & $89(42.0)$ & 0.8 \\
\hline Disciplinary / legal repercussions & $75(35.4)$ & 0.6 \\
\hline Conflict with personal ethics & $74(34.9)$ & 0.8 \\
\hline Concern for patient (i.e., quality of life) & $45(21.3)$ & 0.8 \\
\hline $\begin{array}{l}\text { System concerns (i.e., health care costs for } \\
\text { unwanted resuscitation) }\end{array}$ & $37(17.5)$ & 0.4 \\
\hline $\begin{array}{l}\text { Credibility of DNR order (i.e., coercion, } \\
\text { third-party gain) }\end{array}$ & $28(13.2)$ & 0.4 \\
\hline
\end{tabular}

Table 4. Paramedics' comfort with written and verbal DNR orders

\begin{tabular}{lrrrrrr} 
& \multicolumn{2}{c}{$\begin{array}{c}\text { Written DNR } \\
(n=221)\end{array}$} & & \multicolumn{2}{c}{$\begin{array}{c}\text { Verbal DNR } \\
(n=220)\end{array}$} \\
\cline { 2 - 3 } \cline { 6 - 7 } Comfort level & No. & $(\%)$ & & No. & $(\%)$ \\
\hline Extremely comfortable & 137 & $(62.0)$ & & 48 & $(21.8)$ \\
Comfortable & 60 & $(27.2)$ & & 49 & $(22.3)$ \\
Somewhat comfortable & 15 & $(6.8)$ & & 40 & $(18.2)$ \\
Uncomfortable & 6 & $(2.7)$ & & 49 & $(22.3)$ \\
Extremely uncomfortable & 3 & $(1.4)$ & 34 & $(15.5)$ \\
\hline
\end{tabular}


This study confirms the findings of Adams and coworkers, ${ }^{12}$ who identified informed consent, resource allocation, third-party coercion and patient competence as important sources of ethical conflict faced by paramedics. In the current study, EMT-Ds expressed concern for the system (i.e., inappropriate resource utilization), for the patient (e.g., likely post-resuscitation quality of life, dignity in death) and for the family (e.g., experience of unnecessary emotional trauma). In addition, respondents felt uncertain about the credibility of the DNR order (e.g., whether informed consent had been obtained, the potential for third-party coercion), and reported a personal ethical conflict in the requirement to initiate resuscitation against a patient's express wishes.

Our study revealed that a significant number of EMT-Ds honour DNR orders despite regulations to the contrary. In a similar study, Johnson and Maggiore ${ }^{13}$ demonstrated that $67 \%$ of New Mexico EMTs had withheld resuscitation measures at least once without a direct physician order. An interesting and disconcerting finding in our study was the substantial percentage of respondents who honour DNR orders while giving the appearance (in the documentation) of initiating resuscitation. Such "pseudo-resuscitation" may arise from the reported fear of EMS discipline or legal repercussions.

Partridge and colleagues ${ }^{14}$ found that $96.7 \%$ of EMS providers in the northeastern United States supported legislative changes to permit prehospital advance directives. The majority of respondents in our study were also in favour of a policy change that would allow EMT-Ds to honour prehospital DNR orders, and our EMT-Ds suggested a variety of changes to current resuscitation protocols. Although our purpose was not to develop specific policy proposals (this has been adequately addressed in the literature ${ }^{15-21}$ ), many of our respondents indicated the need for a standardized system, which would include a central registry of patients with DNR orders, an on-scene identification system (e.g., bracelet, infrared sensor) and the development of universal protocols to reduce ethical dilemmas. If legally allowed to comply with DNR orders, respondents were more comfortable with honouring written than verbal DNR orders, because the latter often raised concerns of coercion or third-party gain.

Our EMT-Ds also proposed short-term solutions. They felt that public education about EMS resuscitation guidelines might decrease inappropriate EMS activation, and they recommended that EMT-Ds have radio access to a base hospital physician to facilitate pronouncement of death in the field. Finally, they indicated the need for access to legal counsel in the event they should face criminal charges or a civil suit (e.g., for resuscitating a patient with a DNR order), or departmental discipline (e.g., if they choose to honour DNR orders).
Because of our aging population and an increase in outpatient palliative care, ${ }^{22}$ we anticipate more prehospital encounters with DNR orders in the coming years. These ethical dilemmas will become a growing problem if not addressed in the near future.

\section{Limitations and future questions}

One potential weakness of this study is its relatively low response rate. Our survey addressed sensitive issues, including self-reported policy violations; therefore, it is likely that EMT-D unfamiliarity with survey research and mistrust of EMS administration contributed to our inability to achieve the target response rate of $70 \%$. Although we assured anonymity, paramedics may have been uncertain about this and, as a result, feared disciplinary action. Therefore, the results may not be representative of the entire population of EMT-Ds in this EMS system. Because respondents came from a single metropolitan area, external validity is a concern, and our results may not be generalizable to other EMS systems. Finally, responses may have been subject to recall bias since EMT-Ds were surveyed about past experiences.

Our ongoing research focuses on the response of caregivers who have witnessed unwanted resuscitation attempts (i.e., resuscitation despite a DNR order or advance directive). Future research on survivor responses to unwanted resuscitation or prehospital DNR policies will provide a unique perspective on this issue and may generate recommendations for more uniform and humane regulations.

\section{Conclusions}

EMT-Ds frequently encounter situations in which they are required to resuscitate palliative care patients with DNR orders. Most would be comfortable honouring patient DNR orders if they were legally permitted to, and a significant proportion violate resuscitation guidelines by doing so. Length of EMT-D service was not associated with an increased propensity to honour DNR orders.

The ethical dilemma presented by existing resuscitation guidelines requires immediate attention from regulatory bodies. EMS administrators, medical advisory groups, legislators and regulatory bodies must develop prehospital DNR policies that are operationally feasible, sensitive to survivor needs, and ethically sound.

Acknowledgements: We acknowledge the support and participation of the Level 1 paramedics of Metropolitan Toronto, Ont., and Carla Filies for project administration and manuscript preparation. 


\section{References}

1. Hall S. An analysis of dilemmas posed by prehospital DNR orders. J Emerg Med 1997;15:109-11.

2. American College of Emergency Physicians. "Do not attempt resuscitation" directives in the out-of-hospital setting. Ann Emerg Med 1996;27:684.

3. Emergency Health Services. Manual of operational directives and guidelines - emergency health services. Toronto: Ontario Ministry of Health; 1997.

4. Dull SM, Graves JR, Larsen MP, Cummins RO. Expected death and unwanted resuscitation in the prehospital setting. Ann Emerg Med 1994;23:997-1002.

5. Schmidt TA, Harrahill MA. Family response to out-of-hospital death. Acad Emerg Med 1995;2:513-8.

6. Fitzgerald DJ, Milzman DP, Sulmasy DP. Creating a dignified option: ethical considerations in the formulation of prehospital DNR protocol. Am J Emerg Med 1995;13:223-8.

7. Iserson KV. Foregoing prehospital care: Should ambulance staff always resuscitate? J Med Ethics 1991;17:19-24.

8. Dillman DA. Mail and telephone surveys: the total design method. New York: Wiley; 1978.

9. Gilbert EH, Lowenstein SR, Koziol-McLain J, Barta DC, Steiner J. Chart reviews in emergency medicine research: Where are the methods? Ann Emerg Med 1996;27:305-8.

10. Cohen J. A coefficient of agreement for nominal scales. Educ Psychol Meas 1960;20:37-46.

11. Landis JR, Koch GG. The measurement of observer agreement for categorical data. Biometrics 1977;33:159-74.

12. Adams JG, Arnold R, Siminoff L, Wolfson AB. Ethical conflicts in the prehospital setting. Ann Emerg Med 1992;21:1259-65.

13. Johnson DR, Maggiore WA. Resuscitation decision making by New Mexico emergency medical technicians. Am J Emerg Med 1993;11:139-42.

14. Partridge RA, Virk A, Sayah A, Antosia R. Field experience with prehospital advance directives. Ann Emerg Med 1998;32:589-93.

15. Sosna DP, Christopher M, Pesto MM, Morando DV, Stoddard J. Implementation strategies for a do-not-resuscitate program in the prehospital setting. Ann Emerg Med 1994;23:1042-6.

16. American College of Emergency Physicians. Guidelines for "do not resuscitate" orders in the prehospital setting. Ann Emerg Med 1988; 17:1106-8.

17. Sachs GA, Miles SH, Levin RA. Limiting resuscitation: emerging policy in the emergency medical system. Ann Intern Med 1991;114:151-4.

18. Crabtree JP, Lo AM. Honoring the right to die in medical emergencies. Hawaii Med J 1995;54:476-7.

19. Smith G. New EMS palliative care/DNR protocol will replace existing hospice protocol. Md Med J 1995;44:717-22.

20. Harty-Golder B. Outpatient DNR. J Fla Med Assoc 1994;81:124-6.

21. Rausch PG, Ramzy AI. Development of a palliative care protocol for emergency medical services [editorial]. Ann Emerg Med 1991;20:1383-6.

22. Sager MA, Easterling DV, Kindig DA, Anderson OW. Changes in the location of death after passage of Medicare's prospective payment system. A national study. N Engl J Med 1989;320:433-9.

Correspondence to: Dr. Laurie J. Morrison, Division of Emergency Medicine, Sunnybrook \& Women's College Health Sciences Centre, 2075 Bayview Ave., BG-20 Toronto ON M4N 3M5; fax 416 480-4911, phc.research@utoronto.ca
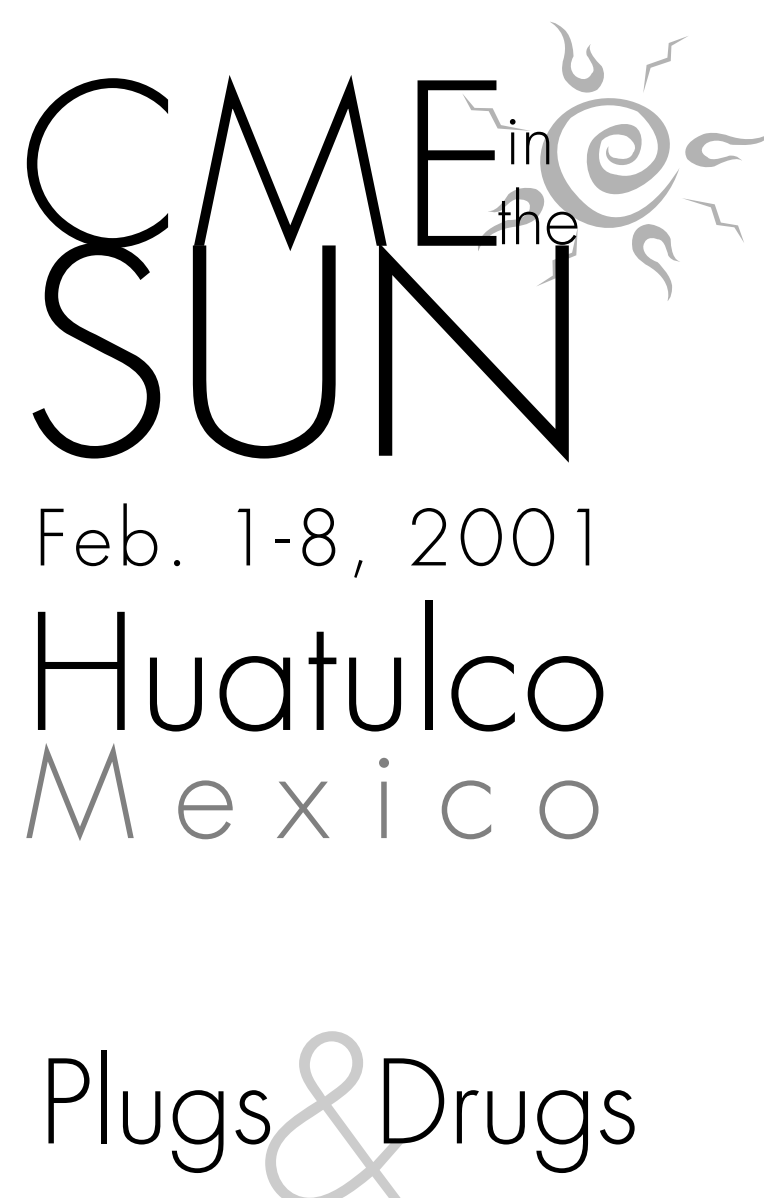

The detection and treatment of thromboembolic disorders in the Emergency Department.

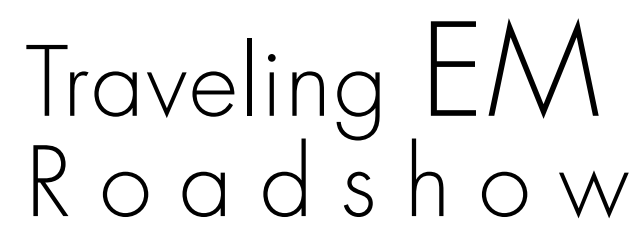

Practical Tips on Everyday Cases
Sponsored by the

Canadian Association of Emergency Physicians

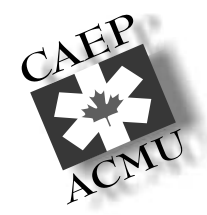

Educational activities are scheduled so attendees can make the most of these vacation venues. 